\title{
SEAWALLS AND BREAKWATERS
}

\author{
James R. Ayers \\ Head, Waterfront Structures \\ Engineering Consultants Branch \\ Bureau of Yards and Docks \\ Washington, D. C.
}

\section{INTRODUCTION}

Since the days of the Phoeniclans and Egyptians, men have struggled to bulld harbor works capable of standing against the forces of the sea. Although the remains of Roman works have endured to the modern era, little progress in design was made until the early part of the last century. Modern developments have led to a better knowledge of wave pressures, but the principal source of guidance is still to be found by studying the causes underlying the disasters of the past.

This paper includes a brief outline of the princlpal stmuctural types which have been built with varying degrees of success, a description of the results of certain model tests on a rubble mound breakwater, and a resumé of some of the most important lessons learned from the many fallures which have occurred.

\section{SEAWALLS}

\section{GENERAL}

A seawall is a shoreline structure built for protecting and stabilizing the shore against erosion resulting from wave action. The design of seawalls is not susceptible to the degree of exactness which has been reached by the science of engineering in many other flelds. The principle cause for this is the wide range in magnitude of the applied forces and the difficulties encountered in attempting to evaluate them. Since most seawalls are filled on the shoreside to a level approximating that of the top of the wall, resistance to wave force 1s provided by the mass of the wall and by the passive resistance of the backfill.

Frequently the seawall occupies such a position with respect to the high and low waterline that a wide expanse of beach and shallow water breaks the primary attacking waves at a distance seaward of the wall, in a succession of progressive steps. In such a case the attacking forces are due to breaking waves of greatly reduced height or. to the onrush of water from broken waves. For locations with high tidal variations, seawalls are subject to a wide range in magnitude of the wave forces. At a certain tide stage, the forces may be those due to reflecting unbroken waves, whereas in other tide stages the full effect of breaking waves must be resisted.

These two types of wave action have long been recognized qualitatively. The theoretical basis for computing pressure due to reflecting unbroken waves has been developed by Sainflou (1928) and verified by several investigators. The existence of the second type of wave pressure, namely that produced by breaking waves, has become established as a result of several years of experimentation in wave pressure measurements by French and Italian investigators (De Rouville, Besson, and Petry, 1938). So far no theoretical method has been developed and accepted for computing pressures from breaking waves although Minikin (1950) has translated the model test work of Bagnold (1938-39) into a workable formula.

For a seawall project of sufficient magnitude, a model test is the most rel1able and expeditious means of determining definite information concerming the behavior of the proposed design, subject to the attack of various assumed conditions of exposure. The prototype must be reproduced accurately in the model to achieve valid results.

As a consideration, second only to effectiveness and stability, the character of the property to be protected -- whether industrial, residential, or recreational - should influence the selection of the type of wall and the architectural treatment of it. 


\section{TYPES OF SEAWALIS}

The topography of the site, extreme tide range, wave characteristics, and foundation conditions will generally determine the type of structure to be bullt. Fig. I iliustrates a version of the gravity section type of seawall. Walls of this type have been built to heights of 50 ft., with their bases extending to a distance of $30 \mathrm{ft}$. below extreme high water level. Early gravity section walls were of dry masonry construction. These were followed in succession by cut-stone or concrete blocks dowelled or keyed together. Still later, cutstone facings set dry, or in mortar, backed with rubble concrete, or concrete, were tried and found to be a defintte improvement. Modern practice is to make the structure as monolithic as possible, eliminating all openings, cracks, and irregularities in the facing.

Fig. 2 represents a minimum construction where poorer foundation conditions exist or where erosion of sand beneath the wall is $11 \mathrm{kely}$. The sheet pile protection has a dual purpose, namely (1) prevention of erosion and (2) support of upper cantilever wall with continuity of bending strength. This wall is suitable for mild wave exposure. It is materially strengthened against vibration and settlement of the backfill by placing reinforcing steel in the paving slab adjacent to the wall and anchoring the slab to the wall.

The wall in Fig. 3 has a curved face. It is founded on plies as required by foundation conditions, and protected against erosion at the toe by sheet piles and rip-rap cover. This wall is sultable for locations having wide beaches with a relatively flat slope of the foreshore. It is effective under moderately severe wave action. In the design of curved face seawalis, the most satisfactory shape seems to be one where the wave path is turned upward at the beach surface and outward, Just below the top of the wall. Experience has Indicated that the curved face is not effective in turning waves whose height is sufficlent to overtop the wall.

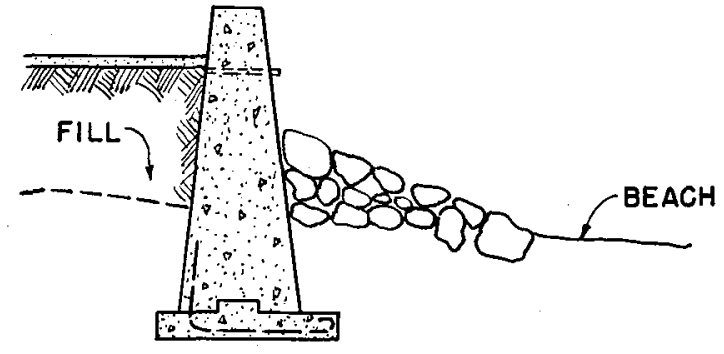

Fig. 1

Seawall -- vertical face.

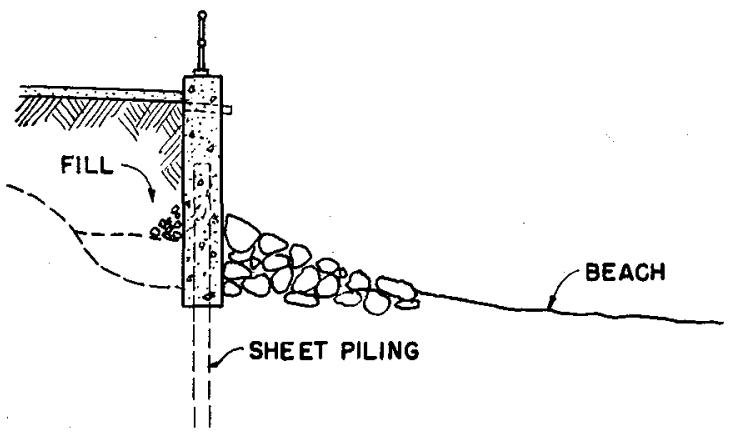

Fig. 2

Seawall -- vertical face.

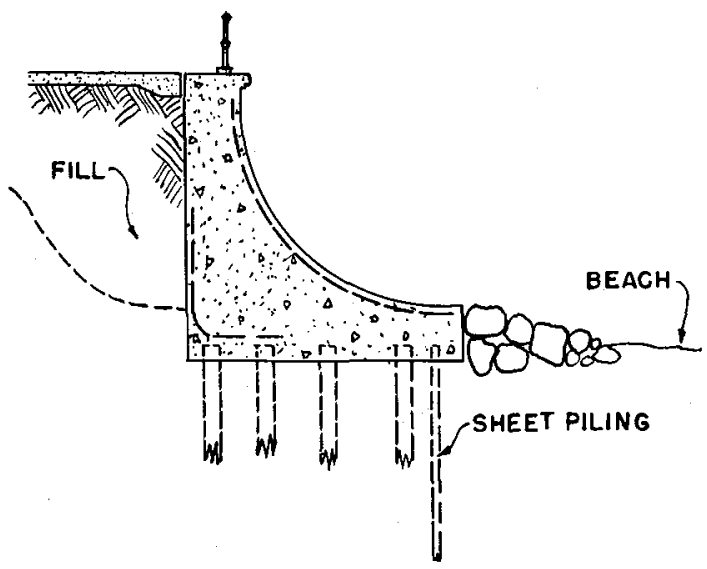

Fig. 3

Seawall -- curved face.

Fig. 4 is an example of a stepped-

face seawall supported on piles and protected at the toe by sheet piling and $r p-$ rap. This wall can be of relatively light construction and is suitable for moderate wave exposure. The stepped-face wall avolds the excessive shock pressures from wave action by forming eddies and air pockets which act as cushions to dissipate the wave energy in a serles of successive stages.

The seawall shown in Fig. 5 is an example of a combination where the waves are dissipated to some extent on the set of inclined steps, and any higher wave motion is turned upward and outward by the curved face of the upper portion. This type is 


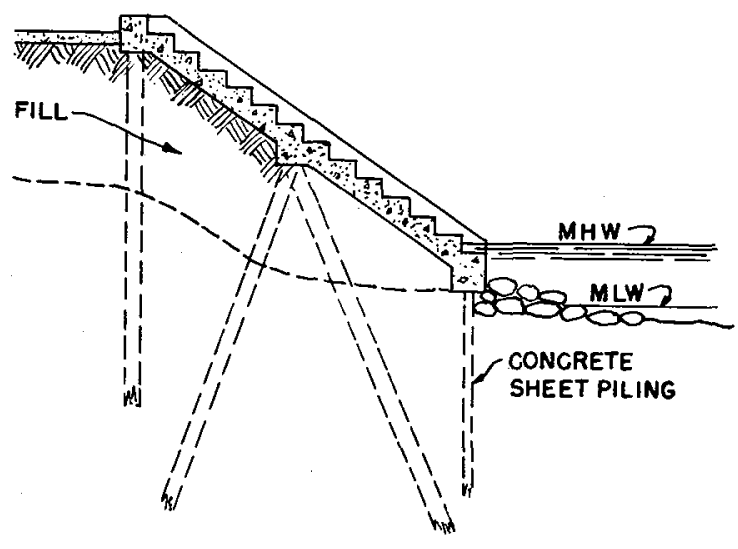

Fig. 4

Seawall -- stepped face.

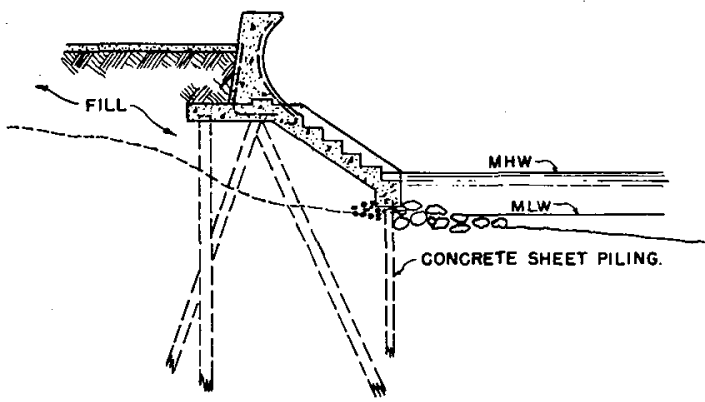

Fig. 5

Seawall -- combination. particularly sulted to locations where the forewhore is narrow and the wave attack moderate. It is adaptable to a wider tidal range than elther the curved or stepped-face used alone.

\section{CAUSES OF FAILURE}

In the early days, when most seawalls were of the gravity type, the principal cause of fallure was dislocation of the stones comprising the wall, followed by the washing out of the backfill and the resultant complete failure of the section. As seawalls have become more monolithic in construction, the principal cause of failure has been due to undermining of the toe or to the development of excessive hydrostatic pressure behind the wall. The latter produces excessive toe pressure followed eventually by settling, tipping and outward wall movement.

Fallures have occurred involving modern type reinforced concrete seawalls due to lack of proper cut-off walls or rip-rap protection for the toe. Fallures due to the impact of falling water behind the wall have eroded the backfill to such an extent as to leave the wall without benefit of horizontal support against the attacking wave forces. In other instances, the construction of a seawall has altered the natural forces in such a manner as to result in the erosion of the foreshore to a depth of several feet in front of and adjacent to the wall.

\section{PROTECTIVE MEASURES}

Experience has demonstrated the necessity for protecting certain vital points, which are most vulnerable to wave attack. The most effective primary protection is the provision of rip-rap of adequate size and extent to prevent the back wash of receding waves from eroding the foreshore. For locations with firm bottom, this may be sufficient. For locations with soft or sandy bottom, sheet plles of adequate length are required to prevent loss of material beneath the wall itself. Adequate toe protection is the most important single precaution which may be taken to prevent overturning of the wall seaward, although proper drainage of the backfill to prevent the development of serious hydrostatic pressure differentials must not be overlooked.

Since the principle resistance to the oncoming wave force is the passive pressure of the earth backfill behind the wall, it follows that erosion in this region must be prevented. The wave attack must be broken sufficiently to prevent throwing of large quantities of water into the air to fall behind the seawall. This is one of the principle reasons for using a stepped-face wall instead of a comparable vertical face. Although a stepped-face wall may be subject to greater wave force, as long as the passive resistance of the backfill is not reduced by erosion, the wall has adequate and lasting stability. Paving over the backfill is an effective means of preventing erosion of the filling material. Adequate protection of the backfill against erosion is the best insurance against overturning of the wall shoreward. 


\section{SEAWALLS AND BREAKWATERS}

After completion of a seawall, the necessity for grolns or other additional foreshore protection should be determined by periodic checking of the foreshore profile.

\section{MAINTENANCE}

A seawall is not a type of structure which may be built and left to perform its function for a long period of time without the necessity for frequent inspection and maintenance. Even after the knowledge of wave action and wall. behavior has progressed much farther than at present, there will be the need for constant vigilance to detect and correct weaknesses after severe storms, which usually occur at first in the form of erosion. The best knowledge now available cannot always predict with certainty just how a wall built at a certain location along a particular alignment will alter the natural forces. Equilibrium may be reached only after the occurrence of several typical storms and the adjustment and replenishment of the foreshore protection. Seawalls built in accordance with knowledge now available, and maintained consistently, can be reasonably expected to have a long useful iffe.

\section{BREAKWATERS}

In contrast to seawalls, fust discussed, which protect a shoreline with the benefit of continuous lateral support from backfill on the shore side, a breakwater is a free standing structure, located in varying depths of water, providing the primary protection for a harbor from the direct action of waves. Where these structures extend into deep water, they are subject to the full fury of the largest ocean waves occurring at the particular location.

\section{GENERAL}

The degree of exposure at a given site is a function not only of the general geographical location with respect to possible wave action, but also of the local hydrography and topography. These include the water depth at the structure, the slope of the bottom, and the tidal range.

The earliest breakwaters were unformed piles of stone of a size that could be handled with the limited equipment available at the time. It soon became evident that the sea slopes were not adequate or the stones of sufficient size to resist the forces delivered by storm waves. Heavy wave action lowered the top of the mound and flattened the seaward slope. It was necessary to constantly replenish the mound until an equilibrium slope was reached. This slope was often found to vary from 1 on 5 to 1 on 10 on the seaward side within the range of the worst attack. Below this level, the slope to the bottom was often as steep as 1 on 1 .

The portion of the mound above low water is extremely vulnerable to injury by storm waves in elther one or both of two different actions. The first is the ralsing and forward transport of the stone by the lncoming waves. The second is the withdrawal and lowering of the stone during the back wash or recoll.

\section{TYPES OF BREAKWATERS}

Rubble mounds have been fashioned in an almost endless varlety of crosssections. In nearly every case, the original shape has been altered by heavy storms after which reshaping and replenishment of stone has been necessary in the damaged areas. An example of a modern type of mound breakwater is shown in Fig. 6 . The large mass of stone is so arranged that the smaller sizes, forming the lower central portion of the core, are protected by the larger stones forming the exterlor slopes and the upper portion, the latter being most severely exposed to direct wave action. The relatively large volume of class $B$ stone indicated is to provide adequate stability during construction.

A mound of rubble stone is indicated where there is an abundant supply of rock available. It is particularly adapted for locations with small tidal range and in depths of water, up to perhaps $60 \mathrm{ft}$. It has the advantage that storm damage or vertical settlement due to a poor foundation site may be repalred by renewing or replacing the dislocated stone. 


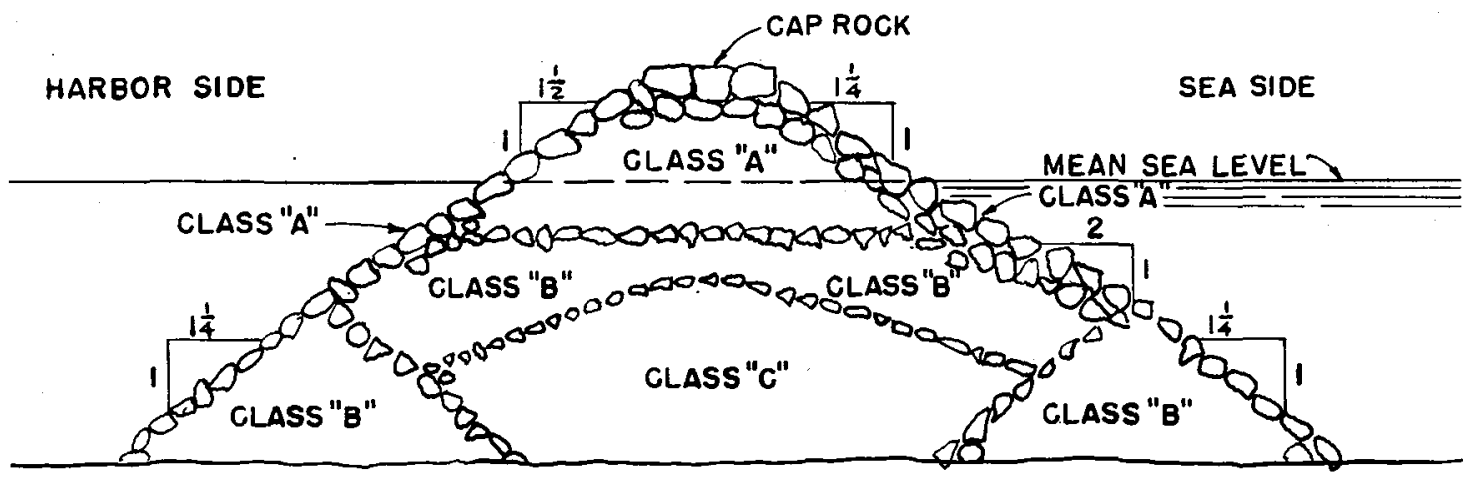

Fig. 6. Breakwater -- rubble mound.

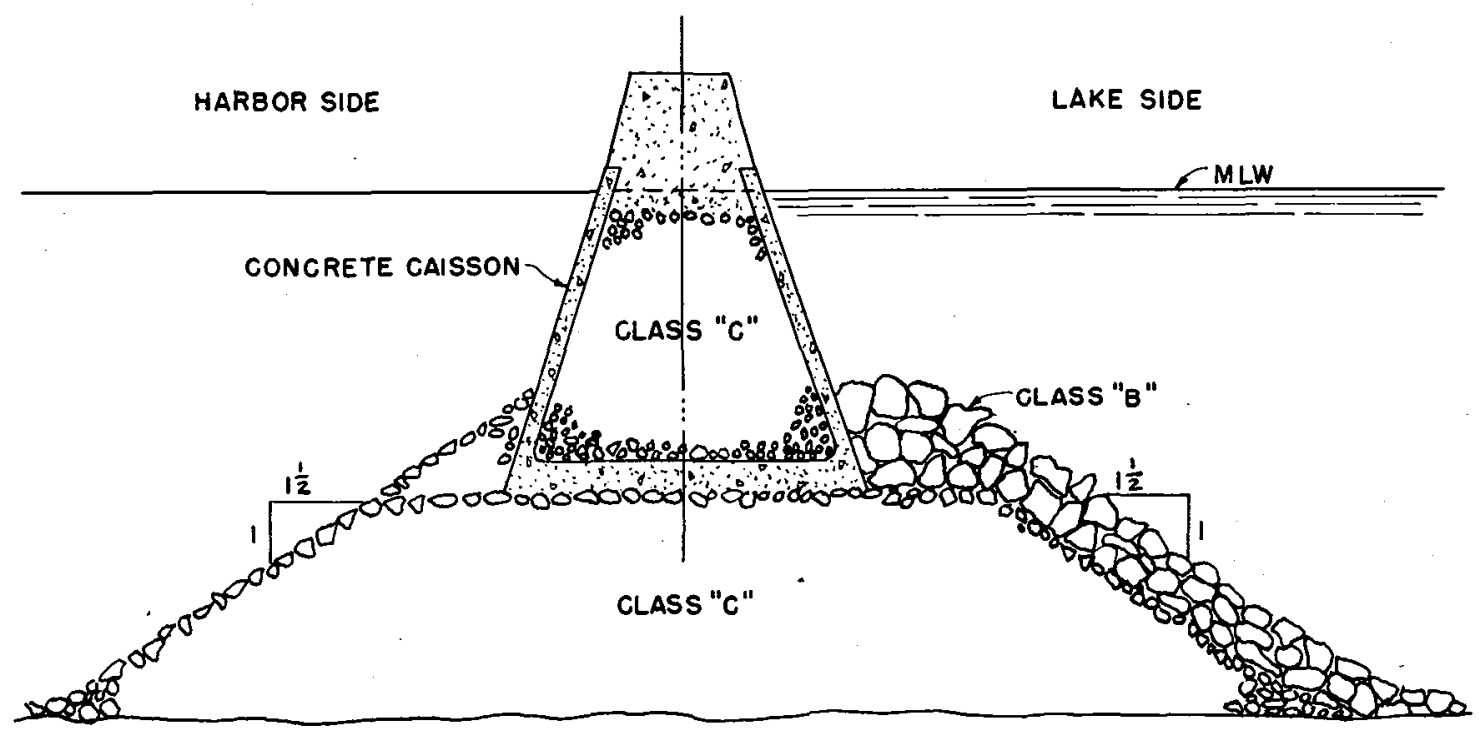

Fig. 7. Breakwater -- composite.

A composite type of breakwater is shown if Fig. 7. For deep water sites and at locations having large tidal variation, the quantity of stone required for a full height rubble mound 1s not economlcally feasible. Such a condition gives rise to comblnations of rubble bases and various types of superstructure. Here the rubble mound provides the base which accommodates itself to the irregularities of the sea bottom, and may be deposited in deep water and allowed to stand for the purpose of obtaining a large part of the total settlement before placing the superstructure. Composite breakwaters of this type may be divided into two classes, namely those with superstructure founded at low water level, and those whose superstructure extends sufficiently far below low water to avoid the breaking of storm waves and disturbance to the rubble base. The class with superstructure founded at low water, most of which were built prior to 1900 , has been located at sites having a great range of tide.

Vertical-face breakwaters have been used extensively in Europe with varying degrees of success. Fig. $8 \mathrm{is}$ such an example. Many arrangements of blocking have been tried. The usual practice is to set the blocks in horizontal courses with joints crossing in all directions, or suitably keyed and dowelled together. This construction has been varied, where differential settlements were expected, by triming the blocks in inclined layers whose slope is about 70 to 75 degrees with the horlzontal. Blocks welghing up to 410 tons and extending throughout the 
full wall thickness of 12 meters have been used in the construction of some of the more modern vertical-face walls.

A modified vertical-face breakwater is shown in Fig. 9. The lower portion is a concrete caisson-type structure, built of prefabricated units and sunk into position on a prepared sea bed. After sinking, the interior is rapidly. filled to water level with sand or gravel, and covered with a protective stone blanket. After initial settlements have occurred, openings between calssons are filled with concrete and a monolithic cap structure is cast on top. The stepped upper monolith will reduce the height and rise of the waves which would otherwise occur at a vertical face, at the expense of greater wave force against the breakwater. Therefore the stepped capping may be of reduced height as compared to a vertical-face superstructure for the same degree of harbor disturbance resulting from overtopping.

The efficacy of this design has not been definitely established. Model studies to determine the total force and height of wave rise against a verticalface breakwater, compared to one modified at the top as shown, would establish the relative merit of the respective designs.

Figs. 10a and 10b illustrate a type of steel sheet pile breakwater adapted to fresh water sites and moderate seasonal wave disturbance. Numerous examples of this construction are found in the Great Lakes. The structure is vulnerable to
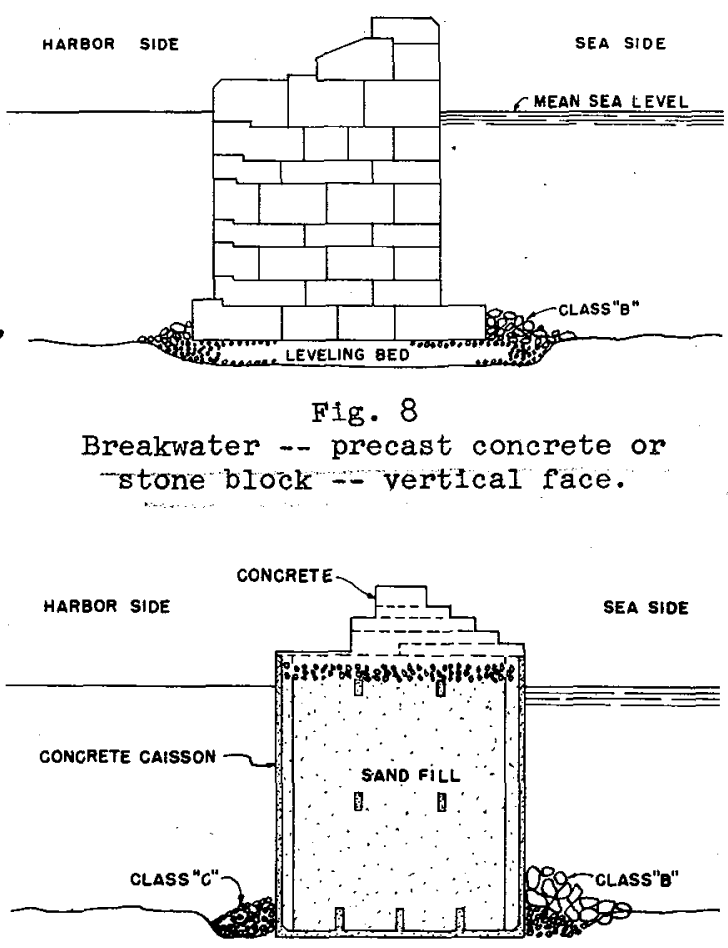

Fig. 9

Breakwater - full calsson

(modifled vertifical face).

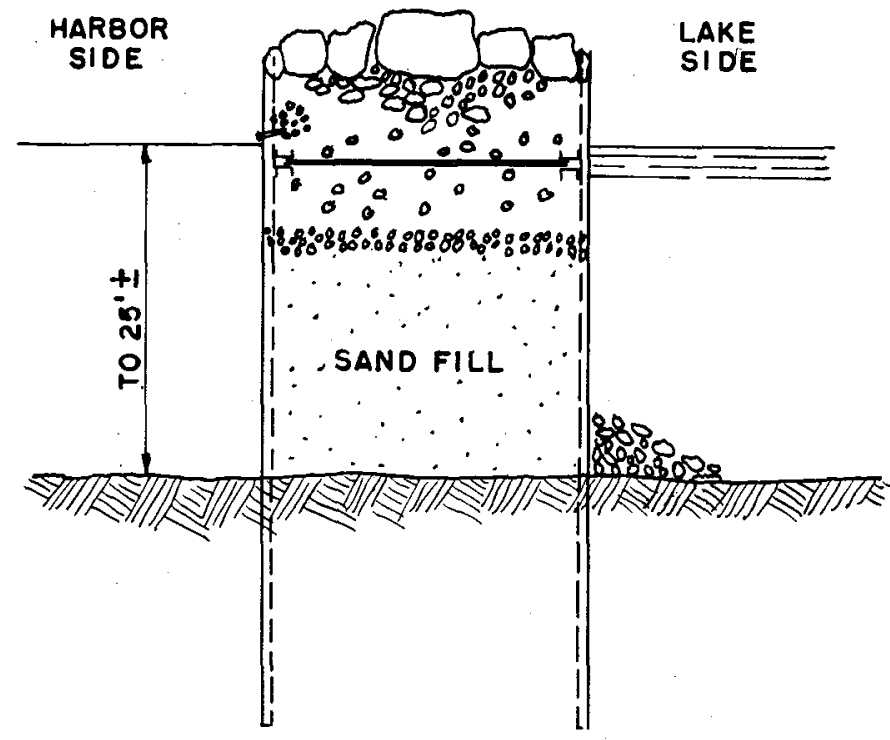

SECTION

FIg. 10a. Breakwater -- steel sheet pile straight wall type.

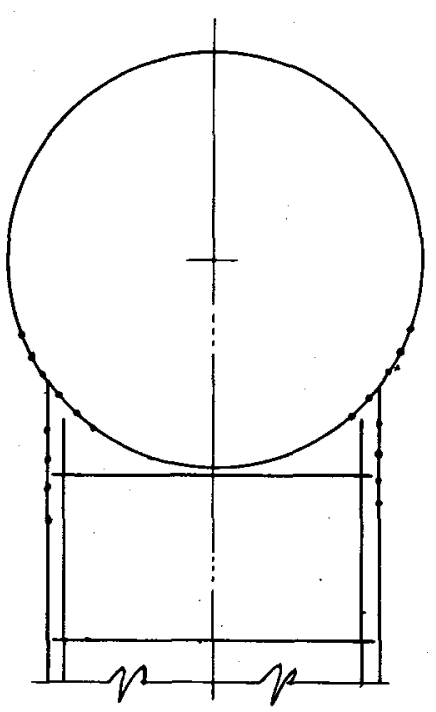

PLAN 


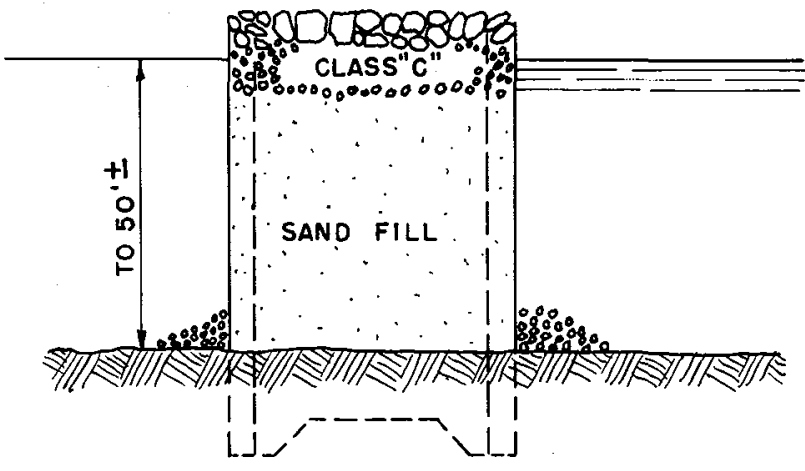

SECTION

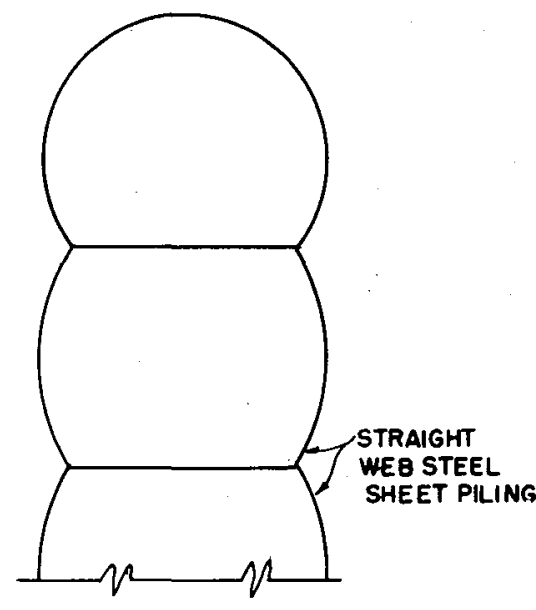

PLAN

Fig. 10b. Breakwater -- steel sheet pile circular type.

storm damage before flliting of the cells during construction, but this can be minimized by proper sequence of building operations.

Many other types of breakwater have been proposed and tried. Among them are pneumatic, or air-bubble breakwaters, floating breakwaters of both vertical and horizontal extent, and submerged barriers. So far as is known, no breakwater installations based on these principles have proven successful in the prototype.

\section{WAVE PRESSURES}

Many investigations have been made to determine the magnitude of wave forces against fixed objects. At present, two general types of wave pressure are recognized, namely first that due to reflected waves and second -- that due to breaking waves. Fig. Il gives the general shape of these two types of pressure diagram. The methods of Sainflou (1928) and Molitor (1935) refer to a form of reflected

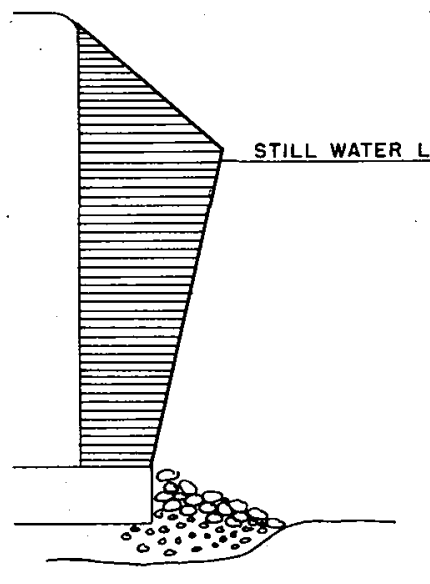

CLAPOTIS

WAVE PRESSURE DIAGRAM SAINFLOU

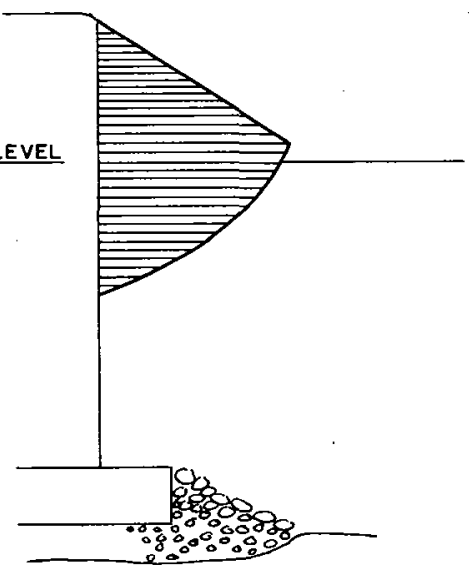

CLAPOTIS WAVE PRESSURE DIAGRAM GAILLARD - MOLITOR

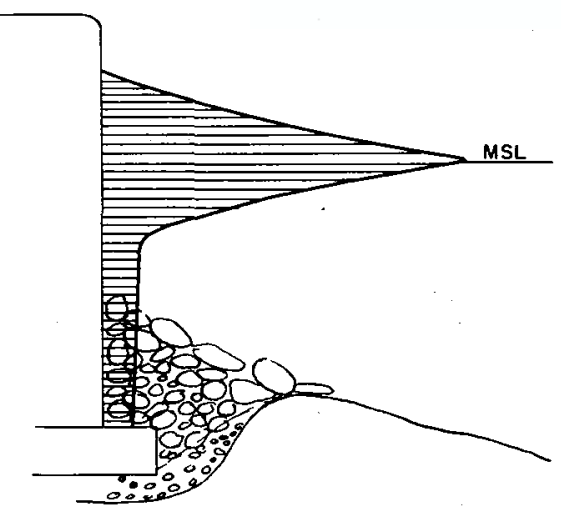

BREAKING WAVE PRESSURE DIAGRAM MINIKIN

Fig. 11 
waves, usually called a clapotis. The methods employed by Lira (1935) closely approximate the analytical solution of Sainflou (1928) while hydraulic model tests conducted in the University of Lausanne, reported by Cagli (1935-36), substantiate to a marked degree the validity of Salnflou's analysis. The method of Minikin (1950) refers to breaking waves and clearly shows the high intensity of pressure developed in the vicinity of mean sea level. The total wave force and overturning effect on a given breakwater are materially increased for the case of breaking waves. Further experimental effort in measuring wave pressures and translation of the results into usable form is most desirable.

\section{MODEL TEST OF RUBBLE-MOUND BREAKWATER}

The many uncertainties attending the study of wave pressure and its effect on breakwaters has led to a search for other methods of investigation. In recent years, the success of model testing in other flelds has suggested the use of this tool to the problem of breakwater stability. Accordingly, the Bureau of Yards and Docks has sponsored a testing program at the Waterways Experiment Station, Vicksburg, Mississippi. The effort has been concentrated on two aspects of the breakwater problem, namely the stability of component materials during various stages of construction and after completion of a breakwater, and the relative stability of stones of varying size and density.

STABILITY OF MATERIALS DURING CONSTRUCTION STAGES

For the purpose of the model study, the ranges of stone weight in the various classifications were as follows:

Class A Stone

$\begin{array}{cr}\text { Percent of total } & \text { Prototype Weight } \\ 75 & 10-12 \text { ton } \\ 20 & 3-9 \text { ton } \\ 5 & 1-2 \text { ton }\end{array}$

Class B Stone

$\begin{array}{rr}15 & 2-4 \text { ton } \\ 30 & 1-2 \text { ton } \\ 15 & 100-10001 \mathrm{~b} \\ 10 & 50-1001 \mathrm{~b} \\ 5 & 20-501 \mathrm{~b} \\ 5 & 10-201 \mathrm{~b} \\ 10 & 5-101 \mathrm{~b} \\ 5 & 1-51 \mathrm{~b} \\ 5 & 1 \text { 1ess than } 1 \mathrm{~b}\end{array}$

Class C Material

$\begin{array}{ll}50 & 0.50-1.001 b \\ 50 & 0.25-0.501 b\end{array}$

The first tests were performed on models of partially completed breakwater sections representative of the various stages of construction on a prototype breakwater. Each tested condition of the model was subjected to wave attack until stab111ty of erosion and displacement had been reached. These tests were 1 imited to the water depth prevalling at the location of the proposed prototype, namely $58 \mathrm{ft}$. Speciflcally, it was desired that the model should yield information of value on the following points :

1. The helght to which the class $C$ material could be constructed without being displaced by wave action before the protective covering (Class B) was placed.

2. The advantages to be gained by placing the Class $B$ stone concurrentiy with the placing of the Class $C$ core material.

3. The amount of covering stone (Class B) necessary to protect the core material (Class $\mathrm{C}$ )

4. The general stability of the completed breakwater section. 


\section{COASTAL ENGINEERING}

Class C material -- unprotected. In testing the stability of the Class C materIa1, four dIfferente partia 1 cross-sections representative of four stages of construction in the prototype, were used. These test sections had top elevations of - $49 \mathrm{ft} .,-38 \mathrm{ft} .$, - $29 \mathrm{ft}$. , and $-24 \mathrm{ft}$., all referred to mean sea level. The model breakwater was subjected to waves of four sizes as follows:
Height
Length
L/H Rat1o
$7.5 \mathrm{ft}$.
$210 \mathrm{ft}$.
28.0
$210 \mathrm{ft}$.
20.0
$270 \mathrm{ft}$.
18.0
$21.0 \mathrm{ft}$.
$300 \mathrm{ft}$.
14.3

OF BREAKWATER

HARBOR SIDE

SEA SIDE

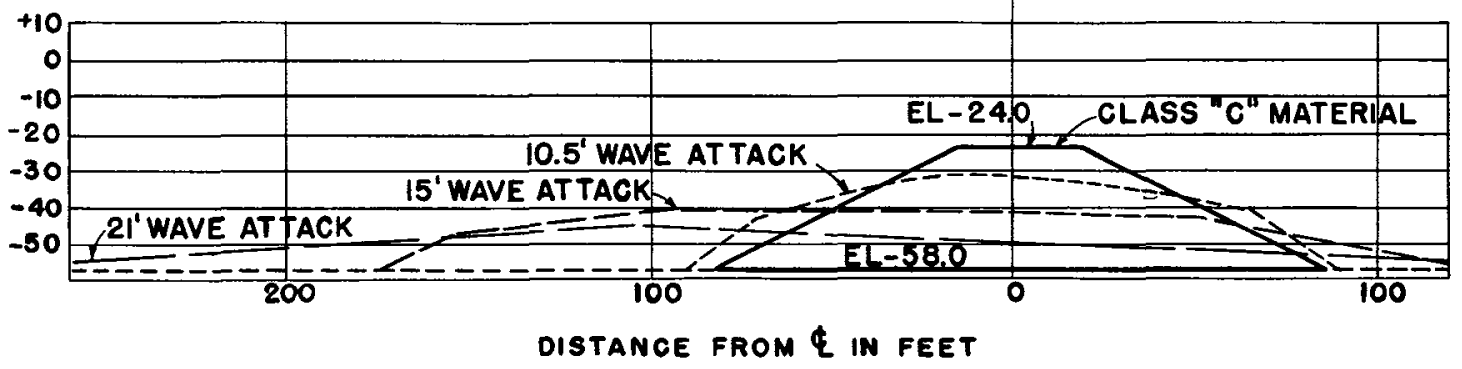

Fig. 12. Displacement of breakwater material by wave action.

Fig. 12 is typlcal for the tests of the $C$ material without enrockment, with top elevation at - $24 \mathrm{ft}$. , and indicates the outline of the damage to the mound by waves $10.5 \mathrm{ft} ., 15.0 \mathrm{ft}$. and $21 \mathrm{ft}$. high. Fig. 13 indicates the heights to which

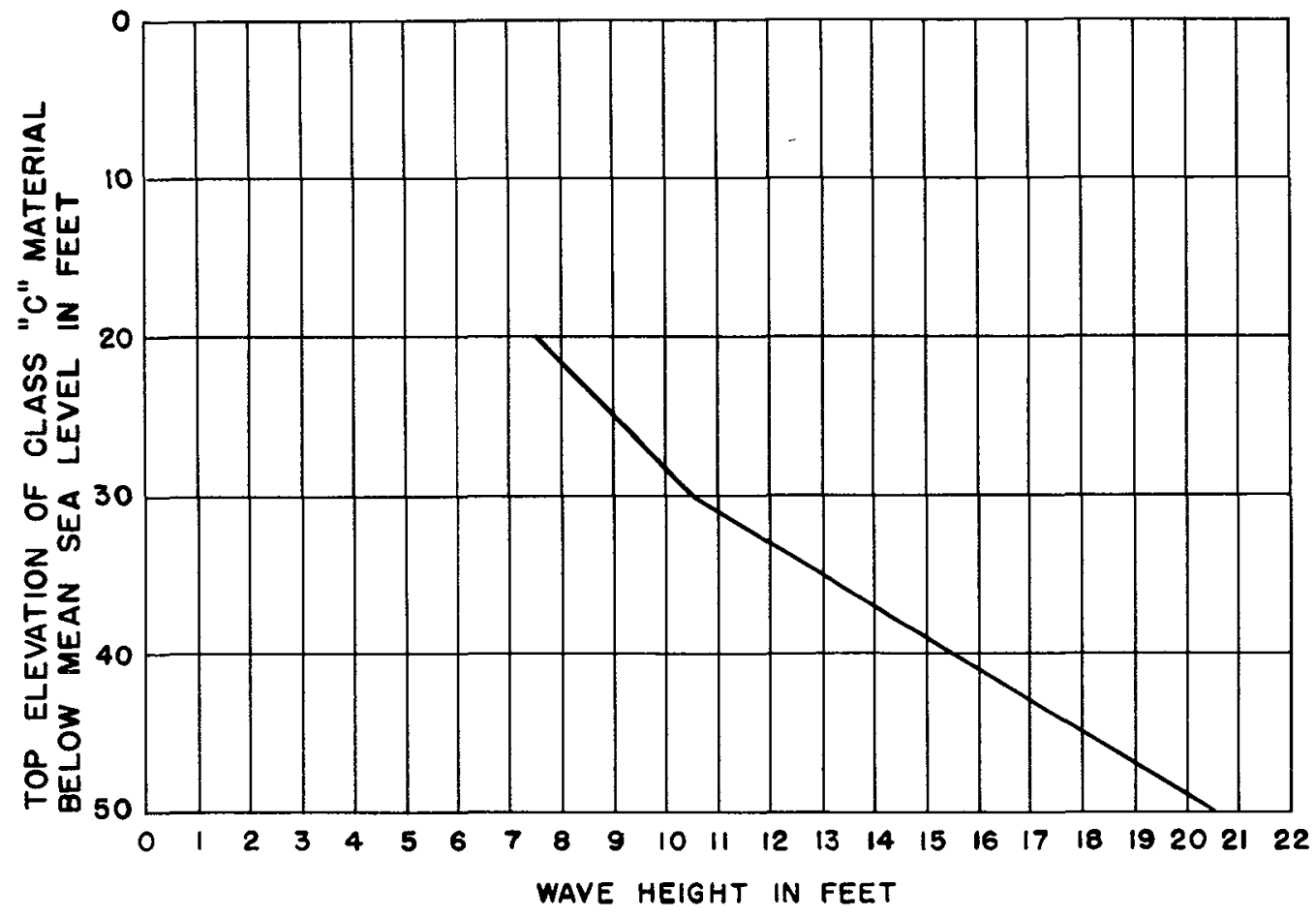

Fig. 13. Stability of class "c" material 
the Class $C$ material may be placed in $58 \mathrm{ft}$. water depth, without displacement of the material outside the design limits, for various wave heights. It will be noted that the wave helghts and corresponding maximum top elevations are as follows:

Wave height
7 to $8 \mathrm{ft}$.
10 to $11 \mathrm{ft}$.
15 to $16 \mathrm{ft}$.
20 to $21 \mathrm{ft}$.

Maximum top elevation of unprotected Class C material

- $20 \mathrm{ft}$, mean sea level

- $30 \mathrm{ft}$.

$-40 \mathrm{ft}$.

$-50 \mathrm{ft}$.

Class C material with Class B stone as toe protection on one side only. Two series" of tests on each of three partial breakwater sections having top elevations of $38 \mathrm{ft} .,-29 \mathrm{ft}$., and - $24 \mathrm{ft}$., mean sea level, were made. One series had Class $B$ stone protection on the harbor side only; the other series had protection on the seaward side only. A typical illustration of the results of the first series is shown on Fig. 14. It appears that there is no particular advantage in

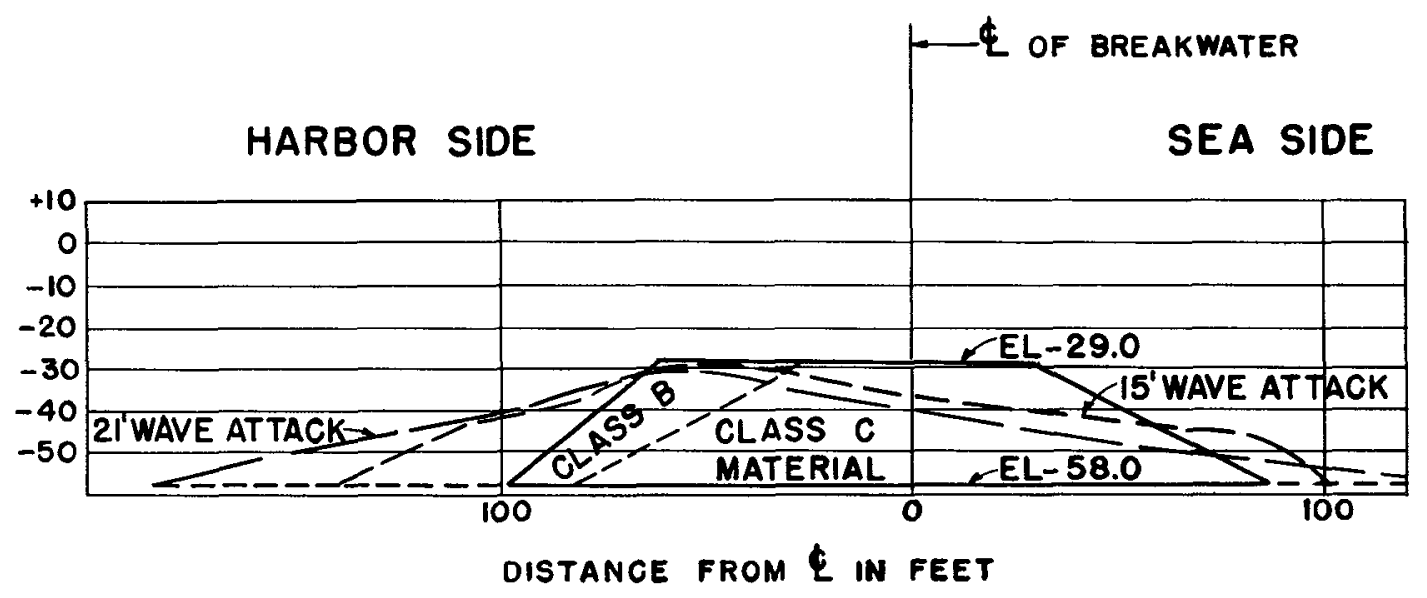

Fig. 14. Displacement of breakwater material by wave action.

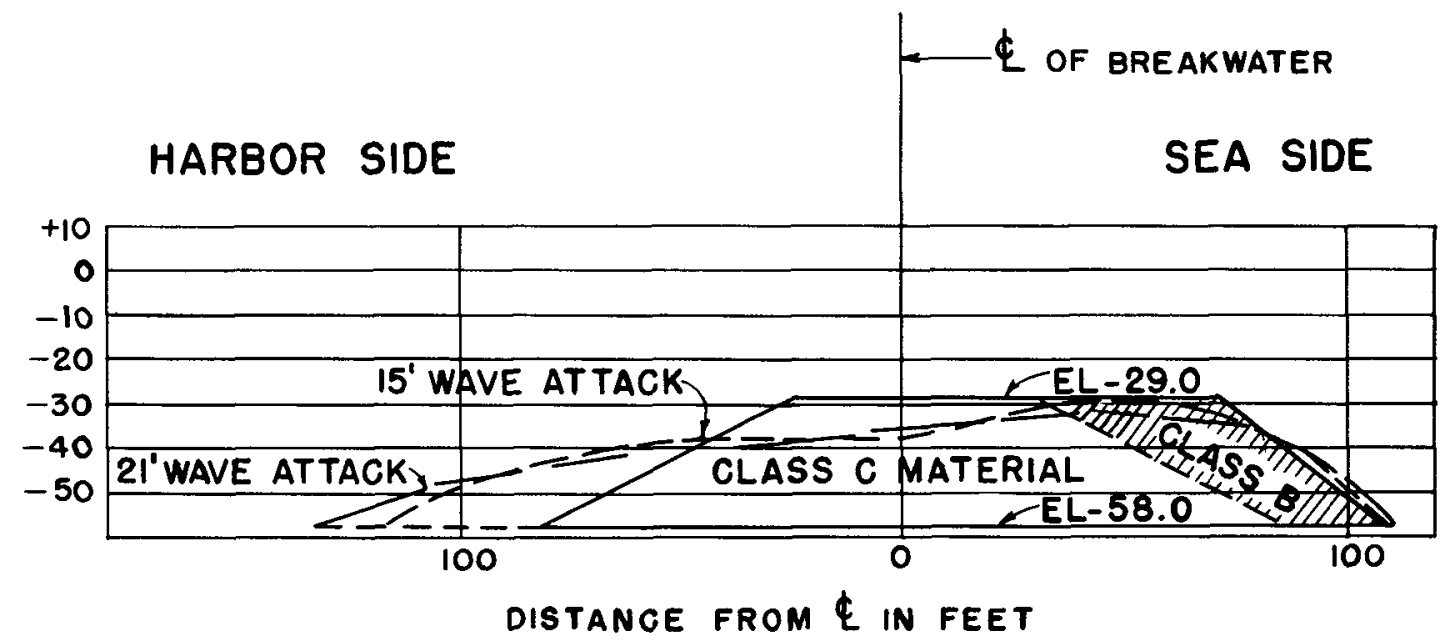

Fig. 15. Displacement of breakwater material by wave action.

adding toe protection on the harbor side only. The waves carried the unprotected Class $C$ material over the Class $B$ material to such an extent that no great saving could be realized by use of this method. Fig. 15 1s typical for the results of 


\section{COASTAL ENGINEERING}

the second series, where Class B protection is provided on the seaward side only. The damage is very similar in type and extent to that of Fig. 14, indicating no advantage over placing the Class B stone on the harbor side only and, for all practical purposes, no advantage over placing the Class $C$ material without toe protection.

Class C material with Class B stone as toe protection on both sides. Fig. 16 shows typical results for tests of partially completed sections with toe protection on both harbor and seaward slopes. For sections of lower elevation, there was considerable displacement of Class $C$ material due to the extensive area of this material exposed to the action of the waves. The resulting scour was concave in shape, with the deposition of the displaced material greatest on the harbor slope. As the top elevations of the sections were ralsed, the exposed area of the Class $C$ material was decreased, and the displacement of material became progressively less. As a result, there was practically no displacement of the class c material for the tests of the section with a top elevation of - $24 \mathrm{ft}$, even during the $21.0 \mathrm{ft}$. wave attack as shown on Fig. 17 .

From a study of these tests, it is concluded that the greatest degree of safety with respect to displacement of materials due to waye attack, is obtained by placing the class B stone on both landward and seaward sides simultaneously.

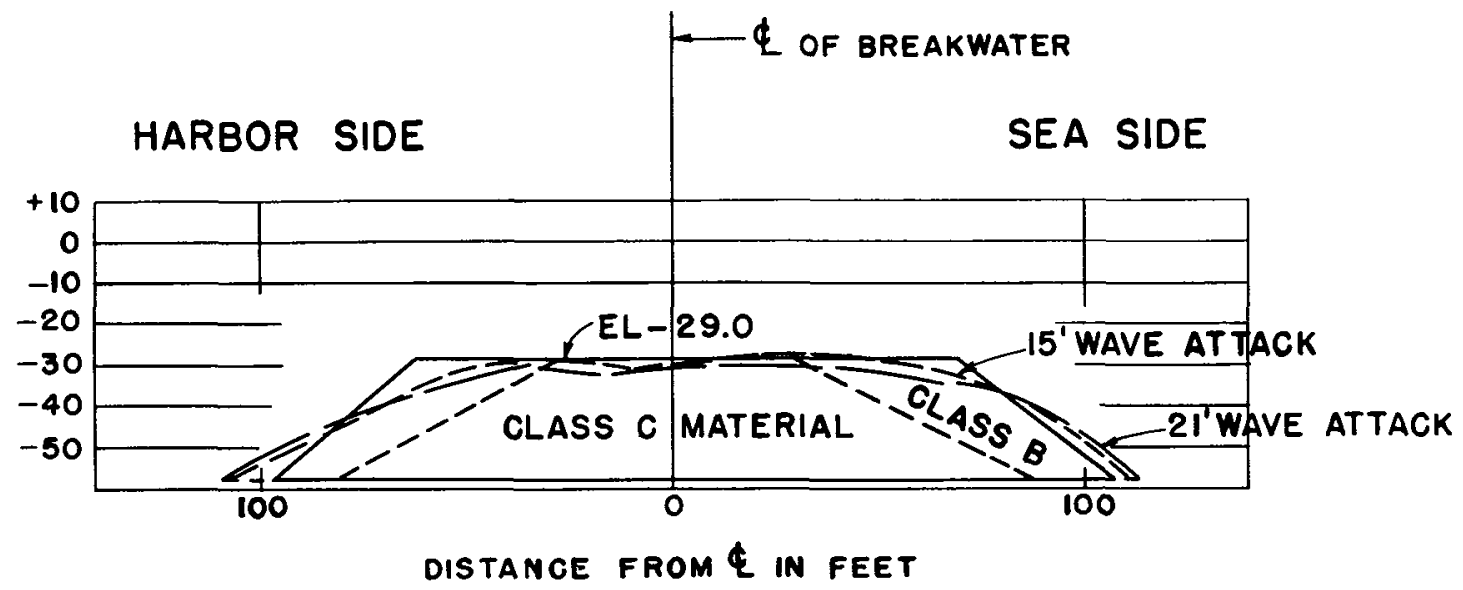

Fig. 16. Displacement of breakwater material by wave action.

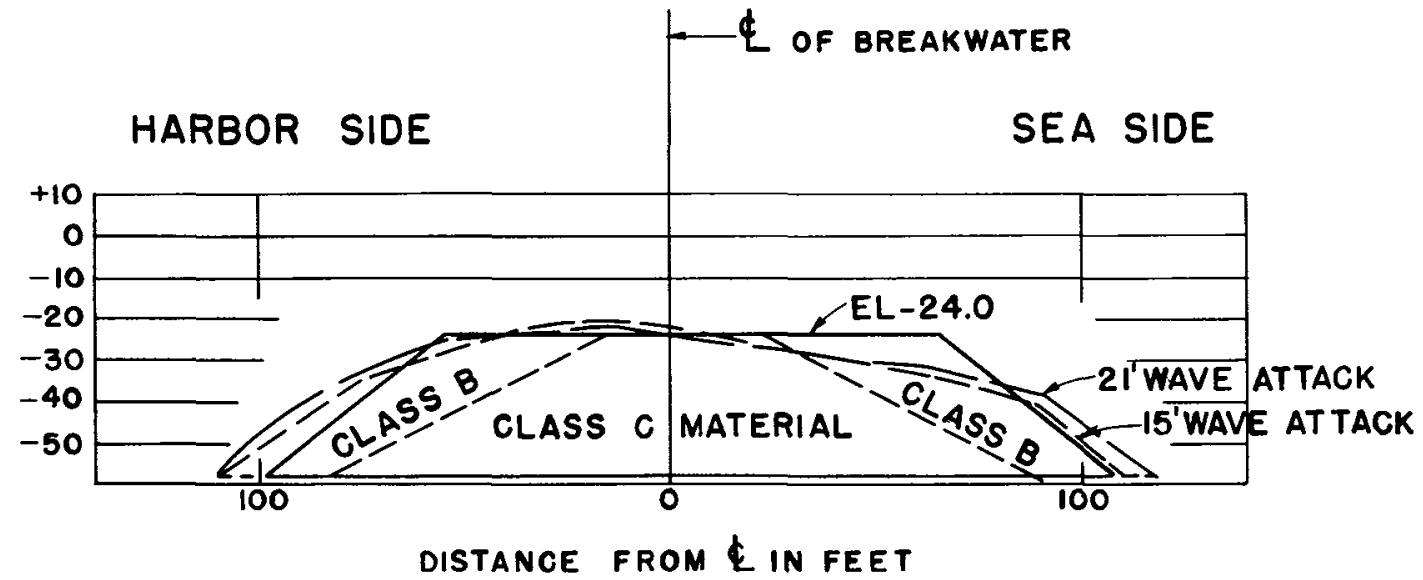

Fig. 17. Displacement of breakwater material by wave action. 


\section{SEAWALLS AND BREAKWATERS}

At lower elevations, the sections would be endangered in severe storms, but the damage would not be entirely detrimental, as the class $C$ material displaced would be washed over the Class $B$ protection on the harbor slope where 1t would not interfere with the future placing of materials. A distinct advantage results from the fact that as the sections are raised in elevation, the area of the Class $C$ materlal exposed to wave action becomes smaller, thus reduclng the displacement.

Completed Class B section. The completed Class B section extending to elevation - $10.0 \mathrm{ft}$. would not stand the attack of $15 \mathrm{ft}$. and $21 \mathrm{ft}$. waves. A prototype breakwater likely to sustain exposure to waves higher than $10 \mathrm{ft}$. during construction would have to be built with flatter slopes than those chosen for this breakwater.

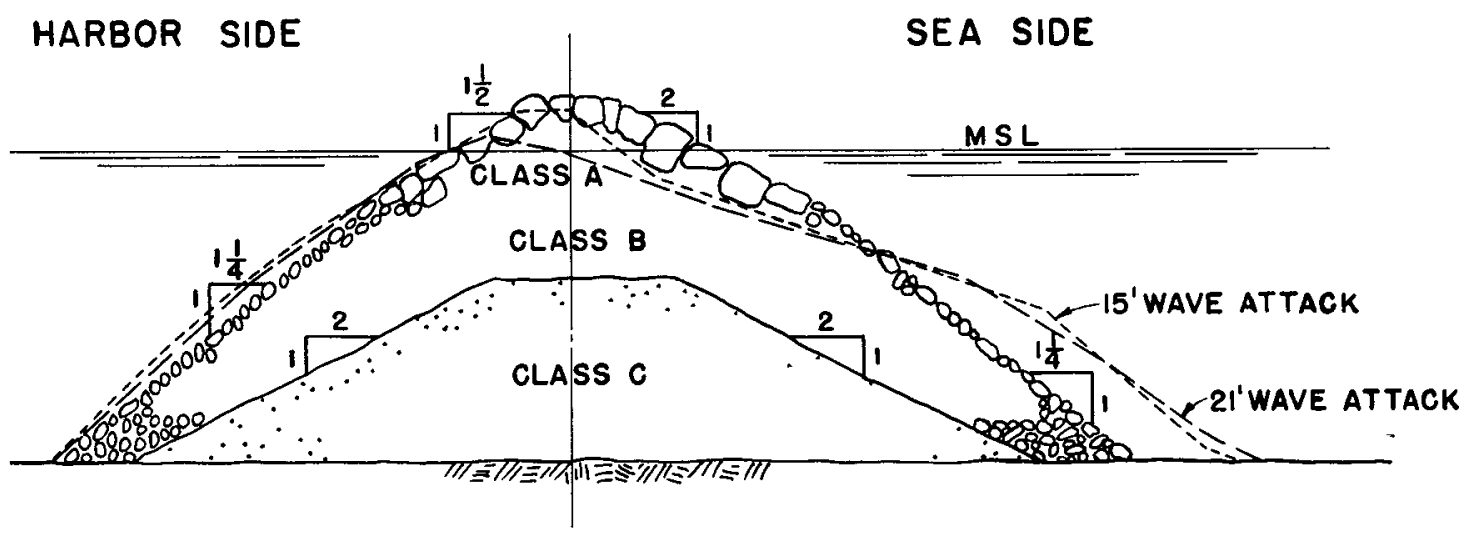

Fig. 18. Breakwater -- rubble mound (model test of stability).

Complete breakwater section. Fig. 18 shows the results of the tests on the complete breakwater section.-Mrinor damage was suffered from the attack of $10 \mathrm{ft}$. waves, but the breakwater failed to maintain its design section under attack by 15 and $21 \mathrm{ft}$. waves. Thus for prototype locations where severe storms occur, the seaward slope should be flatter, with larger cap stone, or the top elevation of the Class $B$ stone and Class C core material should be lowered to about - $20 \mathrm{ft}$. and - $30 \mathrm{ft}$. mean sea level, respectively, thereby increasing the amount of Class A stone.

\section{RELATIVE STABILITY OF STONES OF VARYING SIZE AND DENSITY}

After conclusion of the tests just described, the Bureau of Yards and Docks has sponsored a continuation of the testing program seeking an empirical formula for determining the weight of cap rock required to withstand design waves of various sizes, beginning with an experimental check of the accuracy of the Iribarren formula (see Chapters 23, 24, and 26). The water depth chosen was 90 ft., with a range in size of cap rock from $4-1 / 2$ to 27 tons, wave heights from 5 to 31 ft., wave periods 5 to 13 sec., and side slopes of 1 on $1-1 / 4,1$ on $1-1 / 2,1$ on 2 and 1 on 3 , specific gravity of stone 2.3 to 2.8 . The results of these tests so far have not been completely analyzed. The indications are that the range of conditions covering the design of rubble breakwaters is so wide that separate formulas, or perhaps separate curves for corrective coefficients will be necessary to cover the conditions of (1) no waves overtopping the mound (2) varying depths of wave overtopping.

It is realized that the information gained from this set of tests is very limited, as it applies only to one depth of water and one cross section of prototype breakwater. No quantitative information was obtained regarding the wave forces, as the tangible results appear only in terms of amounts of damage to the section tested by a particular wave. Yet these are indicative of one means of approach through a relatively new medium of controlled study. 


\section{BASIC LESSONS FROM EXPERIENCE}

The lessons learned from experience provide the principal source of present knowledge with respect to breakwater behavior. These lessons are all the more to be respected, as each one has been gained only at the expense of a total or partial failure of many actual structures.

The helght and length of waves assumed for design should be sufficiently large to allow for exceptional storms as yet unknown to the locality.

Stones and blocks should be of adequate size; the smaller the stone, the flatter the sea slopes required for stability.

The destructive influence of the sea extends to considerably greater depths than was originally thought. The core protection must be of sufficient size and extent and carried far enough below water to prevent withdrawal of the smaller core material.

In breakwaters of composite construction, with rubble base and vertical wall, the top of the mound should be located sufficiently far below mean low water to prevent the breaking of the largest waves. The base of the superstructure should be protected by heavy blocks, or rubble, on the benching seaward of the breakwater.

In the case of easily erodible bottom material, a protective blanket, covering the bottom for a considerable width in front of the outer foot of the work, should be provided especially in shallower water.

Superstructures with exposed open folnts are susceptible to severe damage from falling water and the pressure of trapped air.

Vertical face breakwaters should not be built in water of insufficlent depth to maintain oscillatory wave motion. Those founded at the sea bed should be 10cated in water at least twice the helght of the greatest storm waves. Unless the material of the sea bottom is of a flrm or rocky nature, an extensive rubble foundation is necessary to protect the sea floor from erosion for a considerable width in front of the toe.

\section{CONCLUSION}

The rate of progress in the sclence of breakwater design has been slow. Much remains to be discovered, especially in the realm of quantitative expressions for many of the combinations of primary variables. Methods of wave measurement and forecasting will do much to reduce some of the uncertainties of the past.

The science of testing by use of accurately scaled models, where the variables may be rigorously controlled singly and in groups, promises to become the most effective tool yet developed, not only for checking the stability and behav1or of a given design, but also for leading the way to more perfect methods of breakwater analysis.

\section{REFERENCES}

Bagnold, R.A. (1938-39). Interim report on wave-pressure research: Jour. Institution of Civil Engineers, vol. 12, pp. 202-226.

Cagl1, H:C. (1935-36). Italien docks and harbours: Jour. Institution of Clvil Engineers, vol. 1, pp. 465-504.

De Rouville, M.A., Besson, P., and Petry, P. (1938). Etat actuel des etudes internationales sur les efforts dus aux lames: Annales des Ponts et Chaussees, vol. 108, No. 7, Partie Technique, pp. 5-113.

Lira, J. (1935). Design of breakwaters with vertical sides. Effect of wave action. Mathematical determination and methods of construction. Lessons gained from experience: XVI International Congress of Navigation, Brussels, 2nd section; Ocean Navigation, Report 77 , pp. 1-37.

Minikin, R.R. (1950). Winds, waves, and maritime structures; studies in harbour making and in the protection of coasts: Charles Griffin and Co., Ltd., London.

Molitor, D.A. (1935). Wave pressure on sea-walls and breakwaters: Trans. Amer. Soc. Civil Engineers, vol. 100, pp. 984-1002.

Sainflou, G. (1928). Essai sur les digues maritimes verticales: Annales des Ponts et Chaussees, Partie Technique, vol. 98 No. IV, pp. 5-48. 